\title{
Chemical characterization and antioxidant activities of oligomeric and polymeric procyanidin fractions from grape seeds
}

\author{
Isabel Spranger $^{\mathrm{a}, *}$, Baoshan Sun ${ }^{\mathrm{a}}$, Ana M. Mateus ${ }^{\mathrm{a}}$, Vítor de Freitas ${ }^{\mathrm{b}}$, \\ Jorge M. Ricardo-da-Silva ${ }^{c}$ \\ a Estação Vitivinícola Nacional, Instituto Nacional de Recursos Biológicos, Quinta d'Almoinha, 2565-191 Dois Portos, Portugal \\ ${ }^{\mathrm{b}}$ Centro de Investigação, Departamento de Química, Faculdade de Ciências, Universidade do Porto, Rua do Campo Alegre, 687, 4169-007 Porto, Portugal \\ ${ }^{\mathrm{c}}$ Instituto Superior de Agronomia, Universidade Técnica de Lisboa, Tapada da Ajuda, 1349-017 Lisboa, Portugal
}

Received 3 August 2007; received in revised form 25 October 2007; accepted 2 November 2007

\begin{abstract}
Two procyanidin fractions, namely oligomers and polymers isolated from grape seed methanolic extract were characterized. Phenolic composition and procyanidin purity of these fractions were determined by normal-phase and reverse-phase HPLC, thioacidolysis-HPLC, ESI-MS analyses, formaldehyde- $\mathrm{HCl}$ precipitation and elemental analysis. Antioxidant activities of these fractions and other wellknown antioxidants were measured using xanthine-xanthine oxidase system for generating superoxide radical $\left(\left\{\mathrm{O}_{2}^{--}\right\}\right)$, the DPPH (1,1-diphenyl-2-picrylhydrazyl) radical method and the Fenton system for generating hydroxyl radical (HO'). The results showed that both oligomeric and polymeric procyanidin fractions were highly pure, with the degree of polymerization ranging from 2 to $17-18$ and 12 to 32-37, respectively. On the basis of molar concentration, polymeric procyanidins appeared the highest antioxidant activities, followed by oligomeric procyanidins, whereas catechins presented a lower antioxidant activity than its oligomers and polymers. These results indicate that the antioxidant activities of grape seed procyanidins are positively related to their degree of polymerization. Moreover, grape seed procyanidins presented higher antioxidant activities than other well-known antioxidants such as vitamin C, suggesting that grape seed procyanidins might be of interest to be used as alternative antioxidants.
\end{abstract}

(c) 2007 Elsevier Ltd. All rights reserved.

Keywords: Procyanidins; Grape seed; Thioacidolysis; ESI-MS; Antioxidant activities

\section{Introduction}

During the last two decades, many epidemiological studies have shown that moderate consumption of red wine may reduce the mortality rate from coronary heart disease, the socalled "French paradox" theory (apparent compatibility of a high fat diet with low incidence of coronary atherosclerosis) (Carando, Teissedre, \& Cabanis, 1999; Renauld \& De Lorgeril, 1992). The key components in red wine responsible for these beneficial effects are widely considered to be polyphenols, which have been reported to possess various potent biological activities, such as antioxidant, antiviral, enzyme-

\footnotetext{
${ }^{*}$ Corresponding author.

E-mail address: evn.isabel.spranger@mail.net4b.pt (I. Spranger).
}

inhibiting, antitumor and anti-HIV activities (Aviram \& Fuhrman, 1998; Maffei Facino et al., 1994; Ricardo-daSilva, Darmon, Fernández, \& Mitjavila, 1991; Takechi, Tanaka, Takehara, Nonaka, \& Nishioka, 1985). Red wine polyphenols originate essentially from the solid parts of grape during the maceration/fermentation process (Sun, Pinto, Leandro, Ricardo-da-Silva, \& Spranger, 1999a). Furthermore, both in grape and in wine, the major polyphenols are proanthocyanidins (Spranger, Sun, Leandro, Carvalho, \& Belchior, 1998), which are oligomers and polymers of polyhydroxyflavan-3-ol monomer units linked most commonly by acid-labile $4 \rightarrow 8$ and in some cases by $4 \rightarrow 6$ bonds. Proanthocyanidins are secondary plant metabolites and widely distributed in the plant kingdom. The most common class of such compounds are procyanidins, consisting of 
(+)-catechin and (-)-epicatechin units (Porter, 1988). In solid parts of grape cluster, grape seeds are much richer in these phenolic compounds than grape skins and grape stems. Thus, fractionation, isolation, and structural identification of grape seed proanthocyanidins have been extensively studied. Only procyanidin-type of proanthocyanidins, with partial galloylation, were detected in grape seeds (Prieur, Rigaud, Cheynier, \& Moutounet, 1994; Sun, Leandro, Ricardo-daSilva, \& Spranger, 1998). The degree of polymerization may be reached around 30 (Cheynier, 2000; Hayasaka, Waters, Cheynier, Herderich, \& Vidal, 2003; Sun et al., 1998). Several individual dimer and trimer procyanidins were successfully isolated from grape seeds (Ricardo-daSilva, Rigaud, Cheynier, Cheminat, \& Moutounet, 1991; Sun, Belchior, Ricardo-da-Silva, \& Spranger, 1999b).

On the other hand, some biological activities of lowmolecular-weight procyanidins from grape seeds have been studied. Catechins and several dimer and trimer procyanidins from grape seeds appeared potent scavenger capacity for superoxide radical $\left(\left\{\mathrm{O}_{2}^{-}\right\}\right)$and hydroxyl radical (HO') (Ricardo-da-Silva et al., 1991), but little is known about the biological activities of higher oligomeric and polymeric procyanidins from grape seeds. It was reported that proanthocyanidin-rich grape seed extract ( $73.4 \%$ purity) attenuates the development of aortic atherosclerosis in cholesterol-fed rabbits (Yamakoshi, Kataoka, Koga, \& Ariga, 1999). More recently, proanthocyanidin-rich extract from grape seeds was verified to have a preventive effect on cataract formation in hereditary cataractous rats (ICR/ rats) (Yamakoshi, Saito, Kataoka, \& Tokutake, 2002). Furthermore, the proanthocyanidin compositions in these crude phenolic extracts were not well characterized.

The purpose of this work was to characterize chemically and biologically the oligomeric and polymeric procyanidin fractions isolated from grape seeds. The oligomeric and polymeric procyanidin fractions were firstly characterized by normal-phase and reverse-phase HPLC, thioacidolysisHPLC, ESI-MS analysis, formaldehyde- $\mathrm{HCl}$ precipitation and elemental analysis. For the in vitro characterization of the antioxidants, more than one method was used because no one method can give a comprehensive prediction of antioxidant efficacy. So, the antioxidant activities of these two fractions were assessed by several methods: method of Fenton system for generating $\mathrm{HO}^{-}$radical; method of xanthine-xanthine oxidase system for generating $\mathrm{O}_{2}^{--}$, DPPH (1,1-diphenyl-2-picrylhydrazyl) radical method and the method of reducing capacity by Folin-Ciocalteu reagent (FCR). For comparison, some well-known antioxidants and several monomer phenolics were also used in this work as references.

\section{Materials and methods}

\subsection{Commercial reagents}

All commercial reagents were of analytical grade quality. Mannitol, acetylsalicylic acid, L-ascorbic acid, 1,1- diphenyl-2-picrylhydrazyl (DPPH), chelating resin (Chelex 100), Trolox (a water-soluble analogue of vitamin E) were obtained from Sigma-Aldrich (Steinhem, Germany) and ethanol from Merck (Darmstadt, Germany). Gallic acid, $(+)$-catechin, caffeic acid and quercetin were purchased from Fluka A.G. (Buchs, Switzerland). Ultrapure water was obtained from Seralpur PRO 90 CN System (Ransbach-Baumbach, Germany).

\subsection{Preparation of freeze-dried oligomeric and polymeric procyanidin fractions from grape seed}

Grape seeds (Vitis vinifera, cv. Fernão Pires) were ground finely (i.d. $\leqslant 1 \mathrm{~mm}$ ) using an ultra centrifugal mill ZM 100 (Retsch GmbH \& Co. KG, Haan, Germany). The grape seed powder $(200 \mathrm{~g})$ was immediately extracted using firstly $3 \mathrm{~L}$ of methanol-water $(80: 20, \mathrm{v} / \mathrm{v})$ followed by $3 \mathrm{~L}$ acetone-water $(75: 25, \mathrm{v} / \mathrm{v})$ to obtain crude phenolic extract as described earlier (Sun et al., 1999b). After removing organic solvents, the crude phenolic extract was chromatographed on a Lichroprep RP-18 $(200 \times 25 \mathrm{~mm}$ i.d.; 25-40 m particle size; Merck, Darmstadt, Germany) column to isolate catechins, oligomeric fraction $\left(F_{\text {olig }}\right)$ and polymeric procyanidin fraction $\left(F_{\text {poly }}\right)$, with the procedures similar to those already described (Sun et al., 1998). Briefly, elution began with distilled water adjusted to $\mathrm{pH} 7.0$ to eliminate phenolic acids, followed by ethyl acetate to elute catechins and $F_{\text {olig. }}$. The polymeric procyanidins $\left(F_{\text {poly }}\right)$ adsorbed at the top of the bed were eluted with methanol. The ethyl acetate fraction was evaporated at less than $30^{\circ} \mathrm{C}$ to dryness, recovered with distilled water, adjusted to $\mathrm{pH} 7.0$ and re-deposited onto the same pre-conditioned column to isolate catechins and $F_{\text {olig }}$ by elution firstly with diethyl ether and then with methanol. Both $F_{\text {olig }}$ and $F_{\text {poly }}$ were evaporated at less than $30{ }^{\circ} \mathrm{C}$ to dryness and dissolved in water prior to lyophilization. The powders obtained were stored at $-20{ }^{\circ} \mathrm{C}$ until used.

\subsection{Chemical and structural characterization of procyanidin fractions}

\subsubsection{Thioacidolysis-HPLC analysis}

Acid-catalysed degradation of procyanidin fractions in the presence of toluene--thiol, followed by RP-HPLC analysis was performed as already described (Prieur et al., 1994). This permitted to quantify the terminal units (released as monomeric flavan-3-ols) and extension units (released as benzylthioether derivatives) of procyanidins and thus to calculate their mean degree of polymerization (mDP).

\subsubsection{Normal-phase HPLC analysis}

$F_{\text {olig }}$ and $F_{\text {poly }}$ were fractionated by normal-phase HPLC, which permitted to eluate procyanidins in increasing molecular mass order (Prieur et al., 1994; Rigaud, Escribano-Bailon, Prieur, Souquet, \& Cheynier, 1993). The HPLC apparatus was a Hewlett-Packard 1050, 
equipped with a quaternary pump, a thermostat controlling the column temperature, a Rheodyne injector model 7125 and a UV-visible detector (Hewlett-Packard, Waldbronn, Germany). A Millenium 32 chromatography manager software (Milford, MA, USA) was used for data processing. The HPLC column $(250 \times 4 \mathrm{~mm})$ was a cartridge of 5- $\mu \mathrm{m}$ LiChrospher Si 100 (Merck, Darmstadt, Germany) protected with a guard column of the same material. The elution conditions were the same as described (Prieur et al., 1994). The subfractions thus obtained were collected, respectively, in several runs, pooled, gently evaporated but not to dryness at $<30{ }^{\circ} \mathrm{C}$ in several times with addition of water (both to eliminate trifluoroacetic acid and to prevent hydrolysis of procyanidins) and finally evaporated to dryness. The residue of each fraction was dissolved in methanol, followed by thioacidolysis-HPLC and ESI-MS analysis for structural characterization purposes.

\subsubsection{Reverse-phase HPLC-DAD analysis}

Reverse-phase HPLC-DAD was also used to analyze the phenolic composition of $F_{\text {olig }}$ and $F_{\text {poly }}$. The HPLC apparatus is a Waters ${ }^{\mathrm{TM}}$ 600E HPLC system (Waters Corporation, Milford, MA), consisting of a Waters 600 pump with a steel column heater module controlling the column temperature, a Rheodyne injection valve model 7725i, a Waters 996 photodiode array detector monitored by a Waters Millenium 32 chromatography manager software. The column $(250 \times 4 \mathrm{~mm})$ was a cartridge of $4-\mu \mathrm{m}$ Superspher $100 \mathrm{RP}$ 18 (Merck). The elution conditions were as follows: flow rate $1 \mathrm{~mL} / \mathrm{min}$, column temperature $30^{\circ} \mathrm{C}$, injection volume $20 \mu \mathrm{l}$, solvent A: water/formic acid $(98: 2, \mathrm{v} / \mathrm{v})$, solvent B: acetonitrile/water/formic acid (80:18:2, v/v/v). Isocratic elution with $3 \%$ of B in 5 min, followed by gradient elution of $3-35 \%$ of B in $40 \mathrm{~min}, 35-50 \%$ of B in $5 \mathrm{~min}, 50-80 \%$ of $\mathrm{B}$ in $5 \mathrm{~min}$ and finally isocratic elution with $80 \%$ of B in 15 min were used.

\subsubsection{Formaldehyde-HCl precipitation test}

The use of formaldehyde- $\mathrm{HCl}$ precipitation test in this work was to tentatively quantify the relative percentage of flavonoids in $F_{\text {olig }}$ and $F_{\text {poly. }}$. The conditions of the precipitation reaction were identical to those proposed by Kramling and Singleton (1969). Furthermore, $F_{\text {olig }}$ and $F_{\text {poly }}$ were dissolved in ethanol-water solution $(12 \%, v / v)$ and each of them gave a concentration of $1 \mathrm{~g} / \mathrm{L}$. Four large test tubes were used for each sample. Each test tube was added with $10 \mathrm{~mL}$ of the sample, $10 \mathrm{~mL}$ of $\mathrm{HCl}$ solution (concentrated $\mathrm{HCl} / \mathrm{H}_{2} \mathrm{O}=1: 4$, $\mathrm{v} / \mathrm{v})$ and $5 \mathrm{~mL}$ of formaldehyde solution $(8 \mathrm{~g} / \mathrm{L}$ in water). After homogeneity, the tubes were sparged with nitrogen, stoppered and stored under darkness at room temperature for $72 \mathrm{~h}$. Each reaction solution was then centrifuged at $10,000 \mathrm{~g}$ for $20 \mathrm{~min}$. After filtered using $45 \mu \mathrm{m}$ filter, the supernatants of the same sample were combined and gently evaporated at $30^{\circ} \mathrm{C}$ for several times, by addition of distilled water, to eliminate ethanol,
$\mathrm{HCl}$ and formaldehyde, and then concentrated to give about $10 \mathrm{~mL}$ final volume. The aqueous solution was lyophilized and the powder obtained was weighed, which represent the total amount of non-flavonoid compounds in the sample.

\subsubsection{ESI-MS analysis}

ESI-MS analysis was performed using Esquire $3000^{\text {plus }}$ electrospray Ion Trap mass spectrometer (Bruker Daltonics, Bremen, Germany). A Bruker Daltonics system management software was used for system control and data analysis. The procyanidin fractions (lyophilized powders) were dissolved in methanol, in a concentration $100 \mathrm{mg} / \mathrm{L}$. Each solution was infused directly into ESI source with a syringe pump (74900 Series, Cole-Parmer Instrument, Vernon Hills, IL, USA) at a constant flow rate of $180 \mu \mathrm{l} / \mathrm{h}$. Mass spectra were recorded from $\mathrm{m} / z 200$ to 3000 in a negative mode. Other MS analysis conditions are as follows: capillary voltage $-3500 \mathrm{~V}$, nebulizer gas $\left(\mathrm{N}_{2}\right) 10$ (arbitrary units), drying gas $\left(\mathrm{N}_{2}\right)$ temperature $350{ }^{\circ} \mathrm{C}$. For identifying multiply charged ions (from $[\mathrm{M}-2 \mathrm{H}]^{2-}$ to $[\mathrm{M}-6 \mathrm{H}]^{6-}$ ), $\mathrm{m} / \mathrm{z}$ range intervals were scanned from $\mathrm{m} / \mathrm{z} 200-400,400-600$, $600-800$, etc., up to 3000 .

\subsubsection{Ash and mineral analysis}

Ash was analyzed by the standard method recommended (O.I.V., 1990). $\mathrm{Fe}$ and $\mathrm{Cu}$ were determined using atomic absorption spectrometer (Varian AG-20 ABQ, Zug, Switzerland), also according to the standard method recommended (O.I.V., 1990). Heavy metals, i.e. $\mathrm{Pb}$ and $\mathrm{Cd}$ were determined using a Perkin-Elmer Model 4110 ZL graphite furnace atomic absorption spectrometer (Perkin-Elmer Life and Analytical Sciences, Shelton, CT, USA) according to the method proposed (Catarino \& Curvelo-Garcia, 1999).

\subsubsection{Elemental analysis}

The percentages of $\mathrm{C}, \mathrm{H}$ and $\mathrm{N}$ in the samples were determined by Elemental Analyzer (EA-1108, Fisons Instruments, Crawley, UK).

\subsubsection{Total sugar and total nitrogen}

Total sugar and total nitrogen of the samples were analyzed according to the standard methods (CT83, 1988; O.I.V., 1990).

\subsection{Antioxidant activities of oligomeric and polymeric procyanidin fractions}

\subsubsection{Reducing power}

Total phenols assay by Folin-Ciocalteu reagent (FCR) was used to quantify the antioxidant's reducing capacity as suggested by Huang, Ou, and Prior (2005). The experimental conditions were similar to those proposed previously (Brun, 1979). Furthermore, in a $50 \mathrm{~mL}$ volumetric flask containing about $20 \mathrm{~mL}$ of distilled water, the following reagents were added: $0.5 \mathrm{~mL}$ of the tested sample 
$(1.7 \mathrm{mM})$ in ethanol, $2.5 \mathrm{~mL}$ of FCR, $10 \mathrm{~mL}$ of $20 \%$ $\mathrm{Na}_{2} \mathrm{CO}_{3}$ solution. The volume was adjusted to $50 \mathrm{~mL}$. After homogenization, the flask was heated in a bath at $70{ }^{\circ} \mathrm{C}$ for $10 \mathrm{~min}$, and then cooled. The absorbance at $750 \mathrm{~nm}\left(A_{750}\right)$ of the reaction medium was measured in a $1-\mathrm{cm}$ cell against the blank prepared in the same way but pure ethanol was used instead of the sample. The reducing power of the tested antioxidants was expressed as $\mathrm{mM}$ catechin equivalent ( $A_{750}$ of antioxidant $/ A_{750}$ of catechin).

\subsubsection{Scavenging activity on 1,1-diphenyl-2-picrylhidrazyl radical $\left(D P P H^{\cdot}\right)$}

The scavenging effects of the tested samples on 1,1-diphenyl-2-picrylhidrazyl radical (DPPH') was carried out as previously described (Brand-Williams, Cuvelier, \& Berset, 1995; Ohinishi et al., 1994) with slight modification. Briefly, a $0.05 \mathrm{~mL}$ aliquot of tested sample in ethanol (different concentrations) and $2.95 \mathrm{~mL}$ of $\mathrm{DPPH}^{\cdot}$ solution in ethanol $(0.1 \mathrm{mM})$ were added directly to $10 \mathrm{~mm}$ cell with stopper. The mixture was immediately shaken vigorously for $10 \mathrm{~s}$ by a Vortex mixer. Absorbance at $516\left(A_{516}\right)$ was recorded continuously against ethanol as blank reference, using a Shimadzu UV 265 spectrophotometer (Kyoto, Japan), until the reaction reached the steady state. The percentage of the DPPH' remaining at the steady state, which was calculated as $\% \mathrm{DPPH}_{r e m}^{\cdot}=100 \times\left[\mathrm{DPPH}^{*}\right]_{T} /\left[\mathrm{DPPH}^{\cdot}\right]_{T=0}$, was plotted against the molar ratio of the antioxidant to $\mathrm{DPPH}^{\cdot}$. $\mathrm{EC}_{50}$ $\left[(\mathrm{mol} / \mathrm{L})\right.$ of antioxidant $/(\mathrm{mol} / \mathrm{L})$ of $\left.\mathrm{DPPH}^{*}\right]$ is defined as the amount of antioxidant needed to decrease the initial $\mathrm{DPPH}^{-}$concentration by $50 \%$ (Brand-Williams et al., 1995). $T_{\mathrm{EC} 50}$ is the time needed to reach the steady state of the reaction at $\mathrm{EC}_{50}$ concentration (Sánchez-Moreno, Larrauri, \& Saura-Calixto, 1998), which can be obtained from the plot of the molar ratio of antioxidant to DPPH' against the time needed to reach the steady state of the reaction. The results can also be expressed as antiradical power $\left(\mathrm{ARP}=1 / \mathrm{EC}_{50}\right)($ Brand-Williams et al., 1995) and as antiradical efficiency $\left(\mathrm{AE}=1 / \mathrm{EC}_{50} T_{\mathrm{EC} 50}\right)$ (Sánchez-Moreno et al., 1998), which involves the potency $\left(1 / \mathrm{EC}_{50}\right)$ and the reaction time $\left(T_{\mathrm{EC} 50}\right)$.

\subsubsection{Scavenger capacity on superoxide radical $\left(\left\{\mathrm{O}_{2}^{--}\right\}\right)$}

The assay of scavenger capacity of the tested antioxidant compounds on superoxide radical $\left(\left\{\mathrm{O}_{2}^{--}\right\}\right)$was conducted essentially as described earlier (Aruoma, Murcia, Butler, \& Halliwell, 1993). The superoxide anion radical was generated by a xanthine-xanthine oxidase system (McCord \& Fridovich, 1969). Furthermore, the reagents were added directly in the cell in the following order: $1.1 \mathrm{~mL}$ of $\mathrm{KH}_{2} \mathrm{PO}_{4}-\mathrm{KOH}$ buffer $(100 \mathrm{mM}), 0.05 \mathrm{~mL}$ of xanthine $(20 \mathrm{mM}), 0.05 \mathrm{~mL}$ of EDTA $(0.3 \mathrm{mM}), 0.05 \mathrm{~mL}$ of nitroblue tetrazolium (NBT) $(3 \mathrm{mM}), 0.1 \mathrm{~mL}$ of tested sample (variable concentration) and finally, $0.15 \mathrm{~mL}$ of xanthine oxidase freshly diluted in the phosphate buffer to give $1 \mathrm{unit} / \mathrm{mL}$. The reaction began as long as the addition of xanthine oxidase. The absorbance at $560 \mathrm{~nm}\left(A_{560}\right)$ was continuously measured in a $10 \mathrm{~mm}$ stoppered and stirred cell, at $25^{\circ} \mathrm{C}$ for $40 \mathrm{~min}$, against blank samples which did not contain the enzyme. Control was prepared in the same way but ultra-pure water was used instead of the sample. Scavenger activity of each compound on superoxide radical $\left(\left\{\mathrm{O}_{2}^{--}\right\}\right)$was expressed as both initial rate $\left(V_{0}\right)$ of the kinetic reaction and the percentage of inhibition of NBT reduction at maximum absorbance ( $\%$ inhibition), which can be calculated as follows: $V_{0}=\mathrm{d} A_{560} / \mathrm{d} t \quad(t=0) ; \%$ inhibition $=\left(A_{\text {control }}-A_{\text {compound }}\right) / A_{\text {control }} \times 100$, where $t$ is the reaction time, $A_{\text {control }}$ and $A_{\text {compound }}$ are the maximum $A_{560}$ obtained by control and by antioxidant compound, respectively.

\subsubsection{Scavenger capacity on hydroxyl radical ( $\mathrm{HO}^{*}$ )}

Quantification of scavenger capacity of the tested antioxidant compounds on hydroxyl radical (HO') was performed by determining the rate constant of the reaction of the tested antioxidant compound and $\mathrm{HO}^{\circ}$ generated in Fenton system as described (Halliwell, Gutteridge, \& Aruoma, 1987; Ricardo-da-Silva, 1992), with slight modification. Briefly, in each tested tube, the following reagents were added: $0.25 \mathrm{~mL}$ of deoxyribose (DR) $(11.2 \mathrm{mM}), 0.1 \mathrm{~mL}$ of tested sample (in different concentrations), $0.25 \mathrm{~mL}$ of saline phosphate buffer, $\mathrm{pH} 7.4$ $\left(120 \mathrm{mM} \mathrm{K} \mathrm{K}_{2} \mathrm{HPO}_{4} / \mathrm{KH}_{2} \mathrm{PO}_{4}, 160 \mathrm{mM} \mathrm{NaCl}\right), 0.1 \mathrm{~mL}$ of ascorbic acid $(1 \mathrm{mM}), 0.25 \mathrm{~mL}$ of $\mathrm{Fe}^{3+}$-EDTA $(0.800$ $0.832 \mathrm{mM})$ and $0.05 \mathrm{~mL}$ of $\mathrm{H}_{2} \mathrm{O}_{2}(20 \mathrm{mM})$. All solutions were prepared with ultrapure water previously treated with chelating resin. Solutions of iron salts, $\mathrm{H}_{2} \mathrm{O}_{2}$, and ascorbate were made up fresh just before use. After homogeneity, the tubes were incubated at $37^{\circ} \mathrm{C}$, with agitation, for $1 \mathrm{~h}$. The reaction was stopped by addition of $18 \mathrm{~mL}$ of $0.3 \mathrm{~N} \mathrm{HCl}$ and $1 \mathrm{~mL}$ of $1 \%(\mathrm{w} / \mathrm{v})$ thiobarbituric acid (TBA) in $0.05 \mathrm{M} \mathrm{NaOH}$ (Laughton, Halliwell, Evans, \& Hoult, 1989). The tubes were agitated again and incubated at $100{ }^{\circ} \mathrm{C}$ for $15 \mathrm{~min}$ and then cooled by running water. The absorbance at $532 \mathrm{~nm}$ (A) was measured in $10 \mathrm{~mm}$ cell against water. A blank was prepared in the same way using ultrapure water instead of the sample. The rate constant $(k)$ of the reaction of the tested antioxidant compound with $\mathrm{HO}^{\circ}$ could be determined by $k=f \times k_{\mathrm{DR}} \times[\mathrm{DR}] \times A^{\circ}$, where [DR] is the concentration of deoxyribose; $A^{\circ}$ is the absorbance $A$ in the absence of the tested compound; $f$ is the slope of a plot of $1 / A$ against the concentration (M) of the tested compound; $k_{\mathrm{DR}}$ is the rate constant of the reaction of deoxyribose with $\mathrm{HO}^{-}$which is equal to $3.1 \times 10^{9} \mathrm{M}^{-1} \mathrm{~s}^{-1}$ based on pulse radiolysis studies (Halliwell et al., 1987).

\subsection{Statistical analysis}

All analyses were performed in duplicate or triplicate. Differences among the tested samples were determined by analysis of variance (ANOVA) at $p<0.01$ using Statistica vs '98 edition (StatSoft Inc. Tulsa, OK, USA). 


\section{Results}

\subsection{Characterization of procyanidin fractions}

\subsubsection{Thiolysis-HPLC analysis and range of polymerization degree}

Fig. 1A and B present respectively the reverse-phase HPLC chromatograms of thiolysed solution of $F_{\text {olig }}$ and $F_{\text {poly }}$. Based on the relative molar concentration of terminal units in free form (corresponding to peaks 1-3) and extension units in thioether form (corresponding to peaks 4-7), the mDP values of these two fractions can be calculated to be $8.4 \pm 0.15$ and $24.8 \pm 1.62$, indicating that $F_{\text {poly }}$ is much more polymerized than $F_{\text {olig. }}$. Note that these mDP values are lower than those published previously using Tinta Miúda grapevine variety (Sun et al., 1998), due probably to the different grape varieties and/or different grape maturation.

In order to determinate the range of polymerization degree (DP) of the $F_{\text {olig }}$ and $F_{\text {poly }}$, normal-phase HPLC of these two fractions was performed, which permit to fractionate the procyanidin mixture in increasing order of DP. Fig. 2A and B present, respectively, normal-phase HPLC chromatograms of the $F_{\text {olig }}$ and $F_{\text {poly }}$. Thus, 12 major subfractions of the $F_{\text {olig }}$ (i.e. subfraction I-XII) and nine major subfractions of the $F_{\text {poly }}$ (i.e. subfraction $\mathrm{I}^{\prime}-\mathrm{IX}^{\prime}$ ) were isolated. Thioacidolysis of these subfractions followed by reverse-phase HPLC analysis permit to determine not only the $\mathrm{mDP}$ but also structural composition and structural characteristics of procyanidins in each subfractions (Prieur et al., 1994). The compositional data of these subfractions together with those of the $F_{\text {olig }}$ and $F_{\text {poly }}$ are shown in Table 1.

From the results of oligomeric procyanidin fractions (Table 1), it can be seen clearly that normal-phase HPLC eluted procyanidins in the order of increasing molecular mass, which was in agreement with previous authors (Prieur et al., 1994; Rigaud et al., 1993). However, the mDP of the subfractions of polymeric procyanidins increased up to subfraction $\mathrm{VI}^{\prime}$ and decreased in the subsequent ones. The reason for this is probably due to the lower solubility
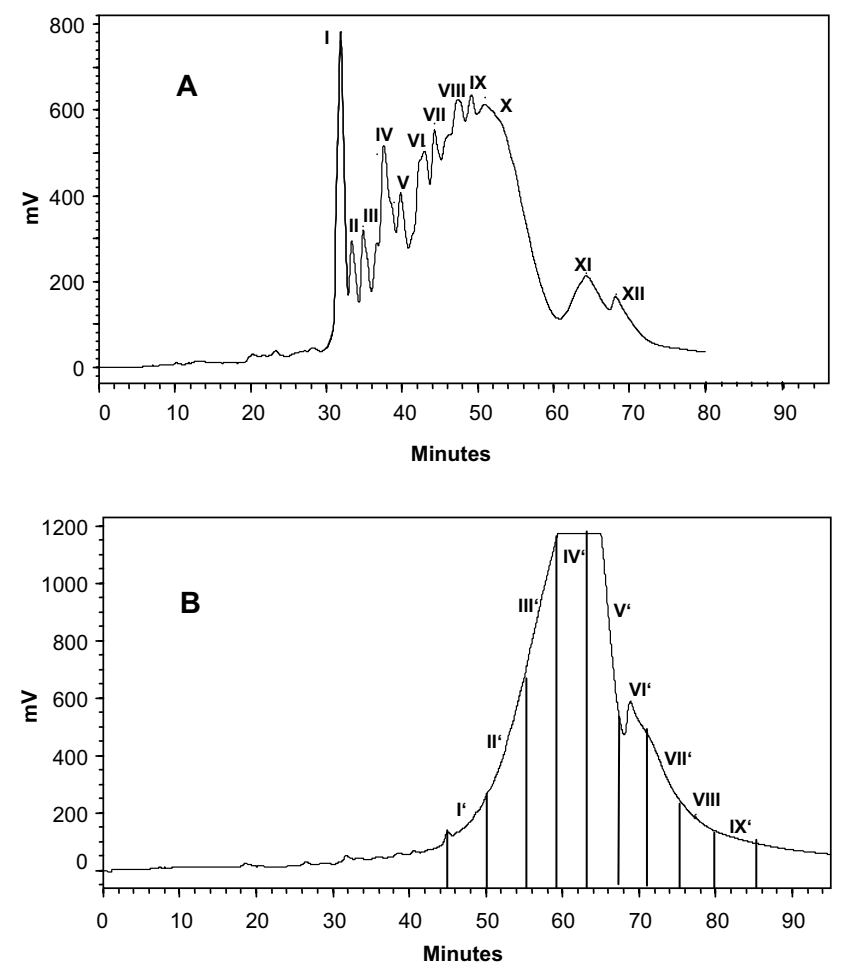

Fig. 2. Normal-phase HPLC chromatograms of: (A) grape seed total oligomeric procyanidin fraction, (B) grape seed total polymeric procyanidin fraction.

of these last subfractions $\left(\mathrm{VII}^{\prime}-\mathrm{IX}^{\prime}\right)$. These results have already been observed on seed and stem tannins by other authors (Labarbe, Cheynier, Brossaud, Souquet, \& Moutounet, 1999; Souquet, Labarbe, Le Guernevé, Cheynier, $\&$ Moutounet, 2000). Furthermore, among the subfractions of $F_{\text {olig, }}$, the last subfraction (subfraction XII) presented the highest $\mathrm{mDP}$ value $(17.8 \pm 0.48)$, while among the subfractions of $F_{\text {poly }}$, the subfraction $\mathrm{VI}^{\prime}$ presented the highest $\mathrm{mDP}$ value $(34.5 \pm 2.89)$.

On the other hand, reverse-phase HPLC analysis showed that all dimeric and trimeric procyanidins were present in
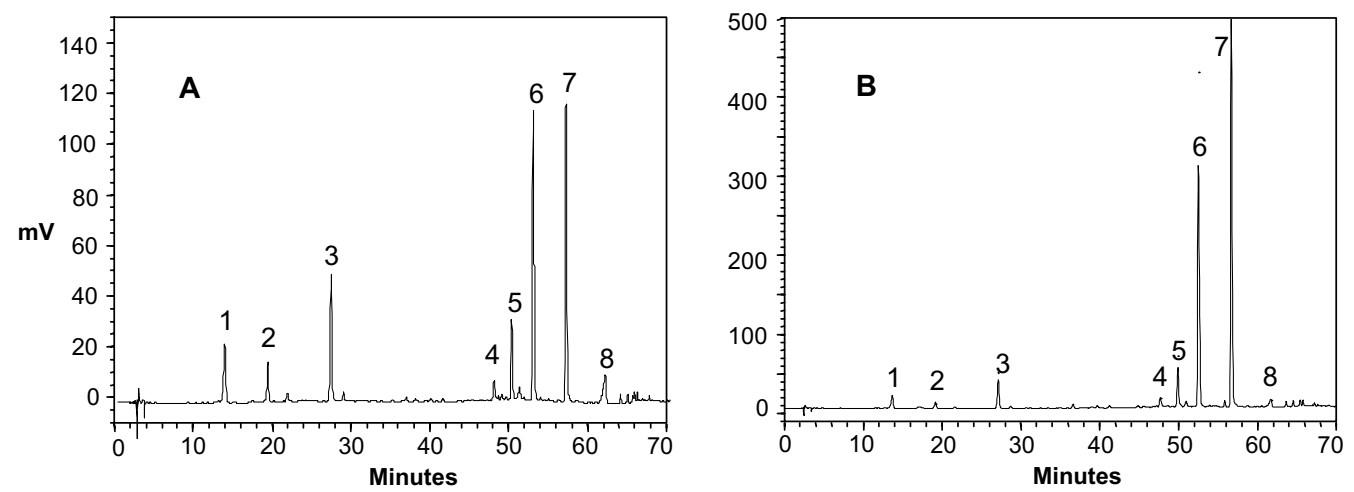

Fig. 1. HPLC chromatogram recorded at $280 \mathrm{~nm}$ of the hydrolyzed total oligomeric procyanidin fraction (A) and the hydrolyzed total polymeric procyanidin fraction (B) with toluene-thiol. 1. (+)-catechin; 2. (-)-epicatechin; 3. (-)-epicatechin 3-O-gallate; 4. thioether of $(+)$-catechin $($ cis $)$; 5. thioether of $(+)$-catechin (trans); 6. thioether of $(-)$-epicatechin; 7. thioether of (-)-epicatechin 3-O-gallate; 8. excessive toluene- $\alpha$-thiol. 
Table 1

Structural composition (Percent in Moles) and characteristics of the subfractions of $F_{\text {olig }}$ in Fig. $2 \mathrm{~A}$ and $F_{\text {poly }}$ in Fig. 2B*

\begin{tabular}{|c|c|c|c|c|c|c|c|c|c|c|}
\hline \multirow[t]{2}{*}{ Fraction } & & \multicolumn{3}{|c|}{ Terminal units } & \multicolumn{3}{|c|}{ Extension units } & \multirow[t]{2}{*}{$\mathrm{mDP}$} & \multirow[t]{2}{*}{$\% G$} & \multirow[t]{2}{*}{$\mathrm{mMM}$} \\
\hline & & Cat & Epi & EpiG & Cat & Epi & EpiG & & & \\
\hline \multicolumn{11}{|c|}{ Oligomer subfraction } \\
\hline \multirow[t]{2}{*}{ I } & $\bar{x}$ & 13.1 & 15.3 & 0.2 & 19.7 & 51.8 & - & 3.5 & 0.2 & 1033.2 \\
\hline & SD & 0.08 & 0.11 & 0.03 & 0.24 & 0.08 & & 0.02 & 0.03 & 9.71 \\
\hline \multirow[t]{2}{*}{ II } & $\bar{x}$ & 20.2 & 6.5 & 3.8 & 51.7 & 17.8 & - & 3.3 & 3.8 & 1522.1 \\
\hline & SD & 0.10 & 0.04 & 0.11 & 0.70 & 0.46 & & 0.03 & 0.11 & 8.93 \\
\hline \multirow[t]{2}{*}{ III } & $\bar{x}$ & 15.5 & 5.2 & 4.8 & 9.6 & 64.0 & 0.9 & 3.9 & 5.7 & 1992.2 \\
\hline & $\mathrm{SD}$ & 1.28 & 0.04 & 0.04 & 0.07 & 1.42 & 0.13 & 0.21 & 0.17 & 34.53 \\
\hline \multirow[t]{2}{*}{ IV } & $\bar{x}$ & 11.0 & 8.2 & 1.5 & 16.7 & 53.4 & 9.2 & 4.8 & 10.7 & 3010.4 \\
\hline & SD & 1.28 & 0.62 & 0.13 & 0.65 & 1.31 & 1.44 & 0.12 & 1.31 & 164.17 \\
\hline \multirow[t]{2}{*}{ V } & $\bar{x}$ & 10.6 & 3.5 & 3.0 & 19.9 & 55.2 & 7.7 & 5.9 & 10.7 & 3305.7 \\
\hline & SD & 0.37 & 0.07 & 0.04 & 0.58 & 0.49 & 0.35 & 0.09 & 0.39 & 84.31 \\
\hline \multirow[t]{2}{*}{ VI } & $\bar{x}$ & 5.7 & 4.7 & 4.6 & 15.1 & 59.3 & 10.6 & 6.7 & 15.2 & 4229.5 \\
\hline & SD & 0.02 & 0.03 & 0.01 & 0.11 & 0.19 & 0.02 & 0.03 & 0.03 & 3.36 \\
\hline \multirow[t]{2}{*}{ VII } & $\bar{x}$ & 6.6 & 3.5 & 2.9 & 12.7 & 52.0 & 22.3 & 7.7 & 25.2 & 6049.2 \\
\hline & $\mathrm{SD}$ & 0.08 & 0.07 & 0.02 & 0.00 & 0.01 & 0.16 & 0.10 & 0.14 & 51.53 \\
\hline \multirow[t]{2}{*}{ VIII } & $\bar{x}$ & 4.3 & 2.6 & 4.4 & 13.0 & 53.7 & 23.0 & 8.8 & 27.4 & 6690.0 \\
\hline & SD & 0.01 & 0.03 & 0.00 & 0.02 & 0.04 & 0.00 & 0.02 & 0.00 & 5.36 \\
\hline \multirow[t]{2}{*}{ IX } & $\bar{x}$ & 3.6 & 1.9 & 4.7 & 11.2 & 51.3 & 27.4 & 9.9 & 32.0 & 7690.8 \\
\hline & SD & 0.09 & 0.10 & 0.02 & 0.06 & 0.01 & 0.03 & 0.02 & 0.05 & 2.67 \\
\hline \multirow[t]{2}{*}{$\mathrm{X}$} & $\bar{x}$ & 2.6 & 1.5 & 5.1 & 9.9 & 45.3 & 35.8 & 11.0 & 40.8 & 9357.4 \\
\hline & $\mathrm{SD}$ & 0.05 & 0.37 & 0.03 & 0.50 & 0.46 & 0.42 & 0.46 & 0.45 & 201.64 \\
\hline \multirow[t]{2}{*}{ XI } & $\bar{x}$ & 1.7 & 2.3 & 4.4 & 8.0 & 36.9 & 46.6 & 11.9 & 51.0 & 11157.3 \\
\hline & $\mathrm{SD}$ & 0.07 & 0.26 & 0.08 & 0.22 & 0.24 & 0.08 & 0.15 & 0.16 & 67.68 \\
\hline \multirow{2}{*}{ XII } & $\bar{x}$ & 1.5 & 2.6 & 1.6 & 8.3 & 51.2 & 34.9 & 17.8 & 36.5 & 10667.0 \\
\hline & SD & 0.63 & 0.90 & 0.41 & 0.25 & 2.09 & 2.49 & 0.48 & 2.08 & 456.62 \\
\hline$F_{\text {olig }}$ & $\bar{x}$ & 4.5 & 4.2 & 3.3 & 13.4 & 49.8 & 24.9 & 8.4 & 28.2 & 6689.5 \\
\hline & SD & 0.01 & 0.24 & 0.03 & 0.68 & 0.20 & 0.84 & 0.15 & 0.86 & 172.34 \\
\hline Polymer & & & & & & & & & & \\
\hline $\mathrm{I}^{\prime}$ & $\bar{x}$ & 9.9 & 10.3 & 1.3 & 13.8 & 57.3 & 7.4 & 4.7 & 8.7 & 2661.9 \\
\hline & SD & 0.18 & 0.48 & 0.06 & 0.01 & 0.32 & 0.04 & 0.08 & 0.02 & 18.98 \\
\hline $\mathrm{II}^{\prime}$ & $\bar{x}$ & 4.1 & 2.4 & 2.1 & 12.5 & 60.9 & 17.9 & 11.6 & 20.0 & 6368.5 \\
\hline & SD & 0.30 & 0.17 & 0.13 & 0.02 & 0.01 & 0.03 & 0.01 & 0.10 & 13.64 \\
\hline $\mathrm{III}^{\prime}$ & $\bar{x}$ & 3.1 & 1.6 & 2.3 & 10.6 & 56.0 & 26.4 & 14.3 & 28.7 & 8450.4 \\
\hline & $\mathrm{SD}$ & 0.22 & 0.04 & 0.08 & 0.21 & 0.68 & 0.37 & 0.19 & 0.29 & 11.23 \\
\hline $\mathrm{IV}^{\prime}$ & $\bar{x}$ & 2.1 & 0.9 & 1.8 & 9.4 & 52.4 & 33.5 & 20.7 & 35.3 & 11311.8 \\
\hline & $\mathrm{SD}$ & 0.09 & 0.14 & 0.01 & 0.50 & 1.49 & 2.21 & 0.95 & 2.22 & 611.00 \\
\hline $\mathrm{V}^{\prime}$ & $\bar{x}$ & 1.3 & 0.7 & 1.3 & 8.7 & 50.5 & 37.6 & 31.0 & 38.9 & 14803.3 \\
\hline & SD & 0.09 & 0.01 & 0.02 & 0.53 & 0.24 & 0.88 & 1.16 & 0.86 & 14803.3 \\
\hline $\mathrm{VI}^{\prime}$ & $\bar{x}$ & 1.3 & 0.5 & 1.1 & 7.5 & 51.0 & 38.7 & 34.5 & 39.8 & 15952.8 \\
\hline & SD & 0.15 & 0.05 & 0.04 & 1.48 & 2.77 & 1.05 & 2.89 & 1.09 & 663.75 \\
\hline $\mathrm{VII}^{\prime}$ & $\bar{x}$ & 1.6 & 1.2 & 1.6 & 8.3 & 51.1 & 36.2 & 22.8 & 37.8 & 12276.6 \\
\hline & SD & 0.27 & 0.29 & 0.14 & 0.17 & 1.04 & 0.71 & 0.81 & 0.86 & 102.91 \\
\hline $\mathrm{VIII}^{\prime}$ & $\bar{x}$ & 1.7 & 1.1 & 1.5 & 10.3 & 52.6 & 32.8 & 23.2 & 34.4 & 11883.4 \\
\hline & $\mathrm{SD}$ & 0.05 & 0.35 & 0.04 & 0.80 & 0.92 & 0.32 & 2.35 & 0.28 & 717.15 \\
\hline $\mathrm{IX}^{\prime}$ & $\bar{x}$ & 2.7 & 1.6 & 1.9 & 10.5 & 55.2 & 26.2 & 16.5 & 30.1 & 9316.1 \\
\hline & SD & 0.38 & 0.31 & 0.02 & 0.06 & 0.95 & 0.22 & 1.81 & 0.20 & 488.86 \\
\hline$F_{\text {poly }}$ & $\bar{x}$ & 1.6 & 0.9 & 1.5 & 8.6 & 54.7 & 32.7 & 24.8 & 34.2 & 12318.2 \\
\hline & SD & 0.12 & 0.11 & 0.05 & 0.46 & 1.25 & 0.69 & 1.62 & 0.78 & 328.56 \\
\hline
\end{tabular}

${ }^{*}$ Cat, Epi, EpiG are the abbreviations for catechin, epicatechin, epicatechin gallate units. mDP signifies mean degree of polymerization, $G$ means degree of galloylation and mMM represents mean molecular mass. $F_{\text {olig }}=$ total oligomeric procyanidin fraction, $F_{\text {poly }}=$ total polymeric procyanidin fraction . Data are mean value of three replicate measurements.

$F_{\text {olig, }}$ (Fig. 3A). The identification of each of these procyanidins was performed by comparison of its retention time with that of the pure compounds isolated from grape seeds as described in our previous work (Sun et al., 1999b), and its identity was confirmed by ESI-MS analysis.

From these results, the range of DP of $F_{\text {olig }}$ might roughly be estimated to be from 2 to $17-18$. Note that the mDP of the first subfraction (subfraction I) of $F_{\text {olig }}$ was 3.5 , not 2 , because the method only estimated the average DP of each subfraction. Similarly, the range of DP of polymeric procyanidins could also roughly be estimated to be from 12 to $32-37$.

It is worth noting that the mDP of the last subfraction of oligomeric procyanidins (subfraction XII) is not the 

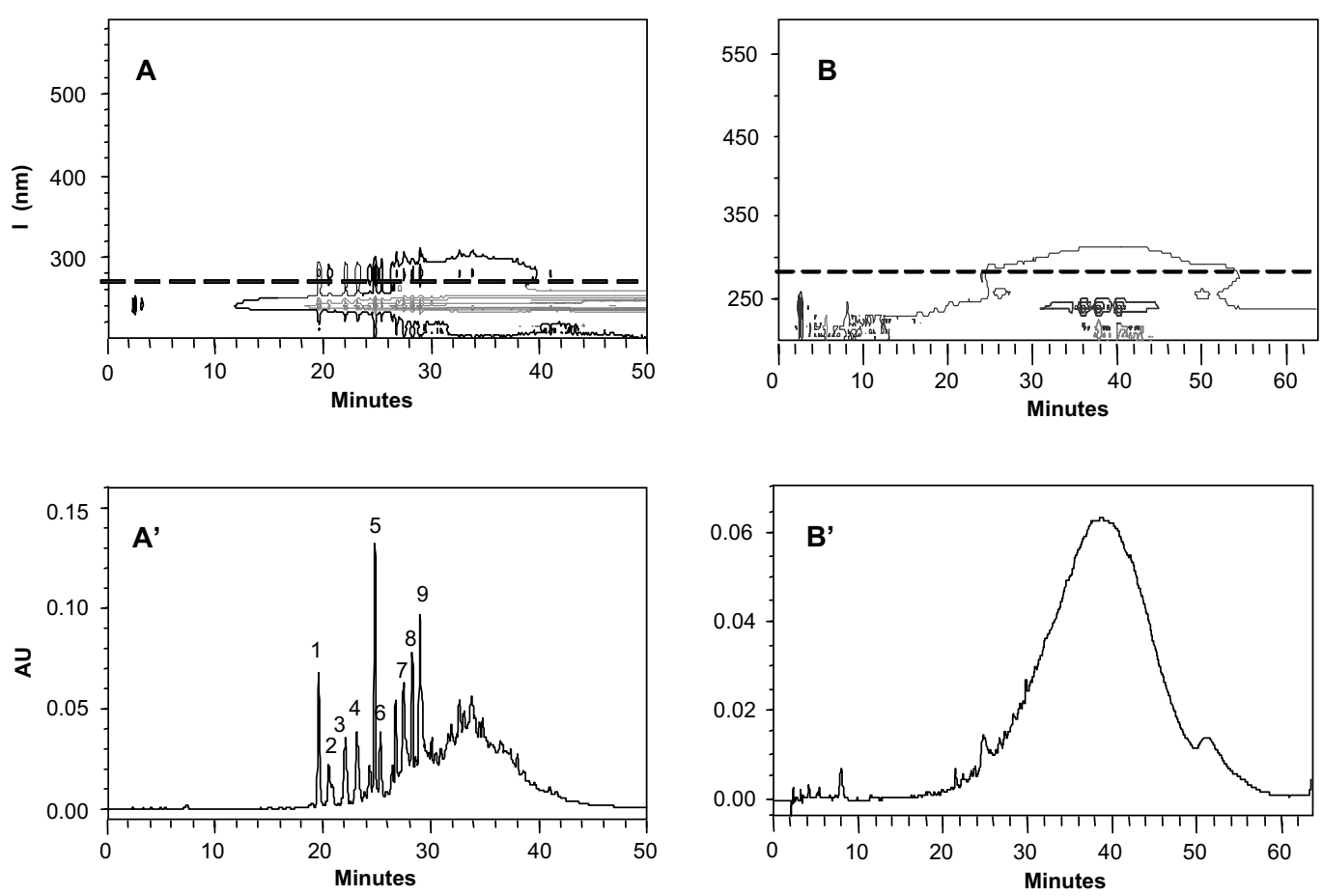

Fig. 3. Photodiode-array HPLC of total oligomeric procyanidin and total polymeric procyanidin fractions. A - PDA contour plot of total oligomeric procyanidin fraction. $\mathrm{A}^{\prime}$ - chromatogram recorded at $280 \mathrm{~nm}$ of total oligomeric procyanidin fraction: 1 . procyanidin $\mathrm{B}_{3} ; 2$. procyanidin $\mathrm{B}_{1} ; 3$. procyanidin $\mathrm{T}_{2} ; 4$. procyanidin $\mathrm{B}_{4} ; 5$. procyanidin $\mathrm{B}_{2} ; 6$. procyanidin $\mathrm{B}_{2}-3-O$-gallate; 7. procyanidin $\mathrm{B}_{2}-3^{\prime}-O$-gallate; 8 . procyanidin $\mathrm{B}_{1}-3-O$-gallate; 9 . procyanidin $\mathrm{C}_{1}$. B - PDA contour plot of total polymeric procyanidin fraction. $\mathrm{B}^{\prime}$ - chromatogram recorded at $280 \mathrm{~nm}$ of total polymeric procyanidin fraction.

same as that of the first fraction of polymeric procyanidins (subfraction $\mathrm{I}^{\prime}$ ), indicating that there was overlap between $F_{\text {olig }}$ and $F_{\text {poly }}$. The reason for this should be due to large structural diversity of higher oligomeric and polymeric procyanidins. However, this overlap was, quantitatively, not very significant.

\subsubsection{ESI-MS analysis}

Various ions $[\mathrm{M}-n \mathrm{H}]^{n-}(n=1-6)$ corresponding to procyanidin molecules were detected in various subfractions from $F_{\text {olig }}$ and $F_{\text {poly }}$. These results are presented in Table 2 and Table 3, respectively. It can be seen that all major di- and trimer procyanidins and other low-molecular-weight procyanidins up to procyanidin with $\mathrm{DP}=15$ were detected in the subfractions of $F_{\text {olig, }}$, while higher molecular mass procyanidins (DP up to 32) were detected in the subfractions of $F_{\text {poly }}$. Furthermore, highest galloylation degrees detected in $F_{\text {olig }}$ (subfraction 14) was 9 while that in $F_{\text {poly }}$ (subfraction IX') reached 15 . The results obtained by ESI-MS are in agreement with those by thioacidolysis-HPLC, although the latter showed the presence of procyanidin molecules with very high galloylation degrees, i.e., 51 in the subfraction XI of $F_{\text {olig }}$ and 39.8 in the subfraction $\mathrm{VI}^{\prime}$ of $F_{\text {poly }}$ (Table 1).

\subsubsection{HPLC-DAD analysis}

Although all phenolic compounds can absorb $280 \mathrm{~nm}$, some of them have additional absorption at wavelength
$>280 \mathrm{~nm}$, i.e., phenolic acids: $313 \mathrm{~nm}$ or nearby; flavonols: $350 \mathrm{~nm}$ or nearby. HPLC analysis with photodiode array detection of $F_{\text {olig }}$ and $F_{\text {poly }}$ (Fig. 3) indicates that phenolic compounds presented in these two samples have little absorption at $\lambda=313$ and $350 \mathrm{~nm}$ as compared with that at $\lambda=280 \mathrm{~nm}$. In addition, the spectrum of any time during elution program for the two samples was identical to that of procyanidins. These results suggest that there are no other types of phenolic compounds such as phenolic acids and flavonols in the two samples. Moreover, degradation of both $F_{\text {olig }}$ and $F_{\text {poly }}$ in the presence of toluene-thiol and at acid medium, followed by HPLC analysis (Fig. 1), revealed that the polyphenols in the hydrolyzed solution were only free flavan-3-ols $((+)$-catechin, $(-)$-epicatechin, and (-)-epicatechin 3-O-gallate) and corresponding thioether derivatives, also supporting that the phenolic compounds in both fractions were only procyanidins.

\subsubsection{Formaldehyde-HCl precipitation method}

It has been known, for a long time, that aldehydes, particularly formaldehyde, can react with flavonoids under acidic condition to polymerize and precipitate (Kramling $\&$ Singleton, 1969). Since the phenolic compounds presented in $F_{\text {olig }}$ and $F_{\text {poly }}$ are only procyanidins, as shown above, the procyanidins in each of these fractions would precipitate by the reaction between procyanidin with formaldehyde. As a result, the supernatant containing nonprocyanidin substances, which represents the impurities 
of these samples, can be lyophilized and weighed. The purity of the procyanidin samples can be calculated as follows: impurities in these two procyanidin fractions. However, these theoretical values were approximate to the measured

Purity $(\%)=\frac{\text { original weight of the sample }- \text { weight of lyophilized supernatant }}{\text { original weight of the sample }} \times 100$

Using this method, the purity of $F_{\text {olig }}$ and $F_{\text {poly }}$ was roughly estimated to be, respectively, $93.0 \pm 1.3 \%$ and $92.2 \pm 1.8 \%$.

\subsubsection{Elemental analysis}

Elemental composition (i.e. element $\mathrm{H}, \mathrm{C}, \mathrm{O}$ and $\mathrm{N}$ ) of $F_{\text {olig }}$ and $F_{\text {poly }}$ was presented in Table 4 . On the basis of the structural compositions of these fractions (Table 1), the theoretical values of the elements in $F_{\text {olig }}$ and $F_{\text {poly }}$ could be calculated. Thus the calculated elemental composition and that determined by Elemental Analyzer can be compared.

It has been shown, from Table 4, that the theoretical values of $\mathrm{C}$ and $\mathrm{H}$ elements in $F_{\text {olig }}$ and $F_{\text {poly }}$ were not exactly the same as the measured ones, indicating that there were ones, suggesting that both $F_{\text {olig }}$ and $F_{\text {poly }}$ possess high purity in procyanidins. These results support those obtained by the Formaldehyde- $\mathrm{HCl}$ precipitation and thioacidolysis-HPLC method. Moreover, only trace of nitrogen $(<0.2 \%)$ found in $F_{\text {olig }}$ and $F_{\text {poly }}$ indicate traces or lack of nitrogenous compounds (including proteins) in these two samples. In fact, we have also determined their total sugars and total nitrogen. Neither sugar nor nitrogen was detected in the two fractions.

\subsubsection{Ash and mineral analysis}

Ash analysis indicated that the ash content of $F_{\text {poly }}$ was very low $(1.5 \pm 0.1 \%)$, while only trace amount of ash was

Table 2

Procyanidins identified by ESI-MS ${ }^{n}$ in the subfractions of $F_{\text {olig }}$ in Fig. 2A

\begin{tabular}{|c|c|c|c|c|c|c|c|c|c|c|c|c|}
\hline \multirow{2}{*}{ DP } & \multicolumn{12}{|c|}{ Subfraction } \\
\hline & I & II & III & IV & $\mathrm{V}$ & VI & VII & VIII & IX & $\mathrm{X}$ & XI & XII \\
\hline \multicolumn{13}{|l|}{1} \\
\hline 2 & $\mathrm{P} 2$ & $\mathrm{P} 2$ & $\mathrm{P} 2$ & $\begin{array}{l}\mathrm{P} 2 \\
\mathrm{P} 2 \mathrm{G} 1\end{array}$ & $\begin{array}{l}\text { P2 } \\
\text { P2G1 }\end{array}$ & P2G1 & $\mathrm{P} 2$ & & & & & \\
\hline 3 & & & P3 & P3 & $\begin{array}{l}\text { P3 } \\
\text { P3G1 }\end{array}$ & P3G1 & $\begin{array}{l}\text { P3G1 } \\
\text { P3G2 }\end{array}$ & $\begin{array}{l}\text { P3 } \\
\text { P3G1 } \\
\text { P3G2 }\end{array}$ & & P3G1 & P3G1 & \\
\hline 4 & & & & & $\mathrm{P} 4$ & $\begin{array}{l}\text { P4 } \\
\text { P4G1 }\end{array}$ & $\begin{array}{l}\text { P4 } \\
\text { P4G1 } \\
\text { P4G3 }\end{array}$ & $\begin{array}{l}\mathrm{P} 4 \mathrm{G} 1 \\
\mathrm{P} 4 \mathrm{G} 2\end{array}$ & $\begin{array}{l}\text { P4 } \\
\text { P4-G1 } \\
\text { P4G2 }\end{array}$ & $\begin{array}{l}\text { P4G1 } \\
\text { P4G2 } \\
\text { P4G3 }\end{array}$ & P4G3 & \\
\hline 5 & & & & & & P5 & $\begin{array}{l}\text { P5 } \\
\text { P5G3 }\end{array}$ & $\begin{array}{l}\text { P5 } \\
\text { P5G1 } \\
\text { P5G2 }\end{array}$ & $\begin{array}{l}\text { P5G1 } \\
\text { P5G2 }\end{array}$ & $\begin{array}{l}\text { P5G1 } \\
\text { P5G2 } \\
\text { P5G3 }\end{array}$ & & \\
\hline 6 & & & & & P6G2 & & $\begin{array}{l}\text { P6G2 } \\
\text { P6G3 }\end{array}$ & & $\begin{array}{l}\text { P6 } \\
\text { P6G1 } \\
\text { P6G4 }\end{array}$ & $\begin{array}{l}\text { P6G1 } \\
\text { P6G2 }\end{array}$ & P6G3 & P6G4 \\
\hline 7 & & & & & P7G2 & & $\mathrm{P} 7 \mathrm{G} 2$ & & & P7G1 & $\begin{array}{l}\text { P7G2 } \\
\text { P7G3 } \\
\text { P7G5 }\end{array}$ & P7G7 \\
\hline 8 & & & & & & & P8G1 & P8G5 & & P8G3 & $\begin{array}{l}\text { P8G1 } \\
\text { P8G3 } \\
\text { P8G4 } \\
\text { P8G6 }\end{array}$ & P8G6 \\
\hline 9 & & & & & & & P9 & & P9G2 & P9G7 & P9G4 & $\begin{array}{l}\text { P9 } \\
\text { P9G4 }\end{array}$ \\
\hline 10 & & & & & & & & & P10 & & $\begin{array}{l}\text { P10G2 } \\
\text { P10G5 }\end{array}$ & \\
\hline 11 & & & & & & & & & & & $\begin{array}{l}\text { P11G5 } \\
\text { P11G8 }\end{array}$ & \\
\hline 12 & & & & & & & & & & & P12G8 & \\
\hline 13 & & & & & & & & & & & P13G7 & \\
\hline 14 & & & & & & & & & & $\begin{array}{l}\text { P14G4 } \\
\text { P14G7 }\end{array}$ & $\begin{array}{l}\text { P14G7 } \\
\text { P14G9 }\end{array}$ & \\
\hline 15 & & & & & & & & & & & P15 & \\
\hline
\end{tabular}

DP: degree of polymerization; $\mathrm{P} x$ : $\mathrm{P}=$ procyanidin, $x=$ number of monomeric units; $\mathrm{G} y: \mathrm{G}=$ galloyl, $y=$ degree of galloylation); $F_{\text {olig }}=$ Total oligomeric procyanidin fraction. Molecular mass of the procyanidins $=290 \times \mathrm{DP}-(\mathrm{DP}-1) \times 2+152 \times y$. 
Table 3

Procyanidins identified by ESI-MS ${ }^{n}$ in the subfractions of $F_{\text {poly }}$ in Fig. $2 \mathrm{~B}$

\begin{tabular}{|c|c|c|c|c|c|c|c|c|c|}
\hline \multirow[t]{2}{*}{$\mathrm{DP}$} & \multicolumn{9}{|c|}{ Subfractions } \\
\hline & $\mathrm{I}^{\prime}$ & $\mathrm{II}^{\prime}$ & $\mathrm{III}^{\prime}$ & $\mathrm{IV}^{\prime}$ & $\mathrm{V}^{\prime}$ & $\mathrm{VI}^{\prime}$ & $\mathrm{VII}^{\prime}$ & VIII' $^{\prime}$ & $\mathrm{IX}^{\prime}$ \\
\hline \multicolumn{10}{|c|}{1} \\
\hline & P3G1 & & & & & & & & \\
\hline \multirow[t]{2}{*}{4} & $\mathrm{P} 4$ & P4G1 & P4G1 & & & & & & \\
\hline & P4G1 & & P4G3 & & & & & & \\
\hline \multirow[t]{2}{*}{6} & & P6 & P6G1 & P6 & P6G3 & & P6G5 & & \\
\hline & & & & & P6G2 & & & & \\
\hline \multirow[t]{2}{*}{7} & P7G2 & & & $\mathrm{P} 7$ & & P7G1 & & P7G5 & \\
\hline & & & & P7G2 & & & & & \\
\hline \multirow[t]{2}{*}{8} & & P8G1 & & P8G6 & P8G2 & P8G2 & & & \\
\hline & & & & & P8G3 & & & & \\
\hline 13 & & & & & P13G7 & P13G10 & & & \\
\hline 14 & & & & P14G8 & P14G5 & & & & P14G4 \\
\hline 15 & & & P15G1 & $\mathrm{P} 15$ & & & P15G11 & P15G4 & \\
\hline 16 & & & & P16G2 & & & & & \\
\hline 17 & & & & P17G2 & P17G15 & & & & \\
\hline 18 & & & P18G6 & & & & & & \\
\hline 19 & & & & & & & P19G12 & & P19G15 \\
\hline 20 & & & P20G2 & & & & & & \\
\hline 21 & & & & & P21G18 & & & & \\
\hline 22 & & & & $\mathrm{P} 22 \mathrm{G} 10$ & & & P22G5 & & \\
\hline 28 & & & & & & & P28G8 & & \\
\hline
\end{tabular}

DP: degree of polymerization; $\mathrm{P} x: \mathrm{P}=$ procyanidin, $x=$ number of monomeric units; $\mathrm{G} y: \mathrm{G}=$ galloyl, $y=$ degree of galloylation); $F_{\text {poly }}=$ Total polymeric procyanidin fraction.

Molecular mass of the procyanidins $=290 \times \mathrm{DP}-(\mathrm{DP}-1) \times 2+152 \times y$.

Table 4

Elemental composition of $F_{\text {olig }}$ and $F_{\text {poly }}$

\begin{tabular}{|c|c|c|c|c|}
\hline \multirow[t]{2}{*}{ Element } & \multicolumn{2}{|l|}{$F_{\text {olig }}$} & \multicolumn{2}{|l|}{$F_{\text {poly }}$} \\
\hline & $\begin{array}{l}\text { Measured } \\
\text { value } \% \\
(w / w)\end{array}$ & $\begin{array}{l}\text { Calculated } \\
\text { value }^{*} \% \\
(\mathrm{w} / \mathrm{w})\end{array}$ & $\begin{array}{l}\text { Measured } \\
\text { value } \% \\
(w / w)\end{array}$ & $\begin{array}{l}\text { Calculated } \\
\text { value }^{*} \% \\
(\mathrm{w} / \mathrm{w})\end{array}$ \\
\hline$\overline{\mathrm{C}}$ & $54.06 \pm 0.18$ & 61.68 & $53.85 \pm 0.04$ & 61.61 \\
\hline $\mathrm{H}$ & $4.41 \pm 0.18$ & 4.09 & $4.99 \pm 0.02$ & 4.03 \\
\hline $\mathrm{N}$ & $<0.2$ & 0 & $<0.2$ & 0 \\
\hline $\mathrm{O}$ & nd & 34.23 & nd & 34.36 \\
\hline
\end{tabular}

${ }^{*}$ The values were calculated on the basis of the structural composition of procyanidins obtained by thiolysis-HPLC analysis (Table 1 and Table 2). Analysis of variance (LSD, $5 \%$ ) indicates that all measured values (mean $\pm \mathrm{SD} ; n=3$ ) were significantly different from their calculated ones. $F_{\text {olig }}=$ Total oligomeric procyanidin fraction; $F_{\text {poly }}=$ Total polymeric procyanidin fraction.

presented in $F_{\text {olig }}(<0.2 \%)$. Furthermore, the contents of several minerals in these two samples were also very low: $0.06 \mathrm{mg} / \mathrm{g} \mathrm{Fe}, 0.12 \mathrm{mg} / \mathrm{g} \mathrm{Cu}$, less than $0.003 \mathrm{mg} / \mathrm{g} \mathrm{Pb}$ and $0.0004 \mathrm{mg} / \mathrm{g} \mathrm{Cd}$ in $F_{\text {olig }}$ and $0.05 \mathrm{mg} / \mathrm{g} \mathrm{Fe}, 0.10 \mathrm{mg} / \mathrm{g} \mathrm{Cu}$,
$0.007 \mathrm{mg} / \mathrm{g} \mathrm{Pb}$ and $0.0002 \mathrm{mg} / \mathrm{g} \mathrm{Cd}$ in $F_{\text {poly }}$. These results indicate only traces or lack of minerals in these two fractions.

Thus, using the methods the most often reported in the literature, both $F_{\text {olig }}$ and $F_{\text {poly }}$ have been verified to be highly pure $(93.0 \pm 1.3 \%$ and $92.2 \pm 1.8 \%$, respectively) and lack of sugars, nitrogenous compounds and several metals. These results provide a base for further studying the chemical properties of these procyanidin samples.

\subsection{Antioxidant activities}

\subsubsection{Reducing Power}

The reducing power of the tested compounds is presented in Table $5 . F_{\text {poly }}$ presents the highest reducing capacity, followed by $F_{\text {olig }}$ and (+)-catechin. The natural antioxidant ascorbic acid and trolox showed very low reducing capacity as compared to $F_{\text {olig }}$ and $F_{\text {poly }}$.

The reducing capacity of a sample is an important parameter reflecting one aspect of its antioxidation property. 
Table 5

FCR reducing capacity

\begin{tabular}{lll}
\hline Antioxidant compound & & $\begin{array}{l}\text { FCR reducing capacity } \\
\text { (mM catechin equivalent) }\end{array}$ \\
\hline Gallic acid & $\bar{x}$ & $0.53 \mathrm{a}$ \\
Ascorbic Acid & $\mathrm{SD}$ & 0.022 \\
Trolox & $\bar{x}$ & $0.42 \mathrm{a}$ \\
& $\mathrm{SD}$ & 0.016 \\
$(+)$-Catechin & $\bar{x}$ & $0.20 \mathrm{a}$ \\
Oligomeric procyanidin fraction & $\mathrm{SD}$ & 0.012 \\
& $\bar{x}$ & $1.00 \mathrm{~b}$ \\
Polymeric procyanidin fraction & $\mathrm{SD}$ & 0.002 \\
& $\mathrm{SD}$ & $4.99 \mathrm{c}$ \\
& $\bar{x}$ & 0.024 \\
& $\mathrm{SD}$ & 0.269 \\
\hline
\end{tabular}

$\bar{x}=$ mean value, $\mathrm{SD}=$ standard deviation. $\quad F_{\text {olig }}=$ Total oligomeric procyanidin fraction; $F_{\text {poly }}=$ Total polymeric procyanidin fraction. Different letter in the same column means very significant differences, $p<$ 0.001 .

However, it might be oversimplified to refer to the result as "total antioxidant capacity" (Huang et al., 2005). To comprehensively study different aspects of antioxidants, other three different reactive species were chosen to verify the antioxidant activity of tested compounds: DPPH', superoxide and hydroxyl radicals.

\subsubsection{DPPH' scavenging activity}

$\mathrm{DPPH}^{*}$ is a useful reagent for studying the free radicalscavenging activities of compounds. Since DPPH radical is not biologically relevant (Barato et al., 2003), the DPPH assay was performed as a preliminary study to estimate the direct free radical scavenging abilities of different tested compounds.

The kinetics of the reaction was dependent on the concentration and structural type of the compound. For each tested compound, the percentage of reducing $\mathrm{DPPH}^{\circ}$ increased dose-dependently at a given concentration range.
According to the plots of percentage of inhibiting $\mathrm{DPPH}^{\cdot}$ (\% inhibition) of each tested compound as a function of the molar ratio of the antioxidant to $\mathrm{DPPH}^{-}$, the relative concentration of each tested compound ( $\mu \mathrm{mol}$ per $\left.\mu \mathrm{mol} \mathrm{DPPH}^{*}\right)$ necessary to reduce $50 \%$ of $\mathrm{DPPH}^{*}\left(\mathrm{EC}_{50}\right)$ can be determined. $\mathrm{EC}_{50}$ is a parameter widely used for the antioxidant capacity of one compound (Vinson, Dabbagh, Sherry, \& Jang, 1995; Yoshida et al., 1989), sometimes expressed as Antiradical power $\left(\mathrm{ARP}=1 / \mathrm{EC}_{50}\right)$ (Brand-Williams et al., 1995). The time to reach a steady state of the reaction at the concentration corresponding to $\mathrm{EC}_{50}\left(T_{\mathrm{EC} 50}\right)$ was also used by several authors for antioxidant classification (Brand-Williams et al., 1995; Sánchez-Moreno et al., 1998). A new parameter considering, both $\mathrm{EC}_{50}$ and $T_{\mathrm{EC} 50}$ was then proposed to discriminate the different antioxidant compounds: Antiradical efficiency (AE) or $1 / \mathrm{EC}_{50} \times T_{\mathrm{EC} 50}$ (Sánchez-Moreno et al., 1998). In this work, all these parameters ( $\mathrm{EC}_{50}, T_{\mathrm{EC} 50}, \mathrm{ARP}$ and $\left.\mathrm{AE}\right)$ for the tested compounds were determined or calculated and the results are presented in Table 6.

According to parameter $\mathrm{EC}_{50}$ or ARP, $F_{\text {poly }}$ presents the highest scavenging activity on DPPH', followed by $F_{\text {olig }}$, whereas natural antioxidant ascorbic acid and other simple phenolics (including catechin) present very low scavenging activity on DPPH: The scavenging activity of grape seed procyanidins on $\mathrm{DPPH}^{-}$is positively related to their degree of polymerization, i.e., polymer $>$ oligomer $>$ monomer (catechin). When Antiradical efficiency (AE) was used to discriminate the different antioxidant compounds, $F_{\text {poly }}$ presents also the highest values, followed by ascorbic acid and $F_{\text {olig, }}$, while other phenolics present low antiradical efficiency. It is worth mentioning that $T_{\mathrm{EC} 50}$ is also another important parameter reflecting the antiradical efficiency of an antioxidant compound. Lower $T_{\mathrm{EC} 50}$ signifies higher antiradical efficiency of an antioxidant compound. Table 6 shows that $(+)$-catechin has a little lower $\mathrm{EC}_{50}$ but much higher $T_{\mathrm{EC} 50}$ than ascorbic acid, so the $\mathrm{AE}$ of $(+)$-catechin

Table 6

Scavenging activity of various antioxidant compounds on DPPH radical

\begin{tabular}{|c|c|c|c|c|c|}
\hline Antioxidant compound & & $\mathrm{EC}_{50}($ moles $\mathrm{AO} /$ moles DPPH $)$ & $T_{\mathrm{EC} 50}(\min )$ & $\operatorname{ARP}\left(1 / \mathrm{EC}_{50}\right)$ & $\operatorname{AE}\left(1 / \mathrm{EC}_{50} \times T_{\mathrm{EC} 50}\right)$ \\
\hline \multirow[t]{2}{*}{ Caffeic acid } & $\bar{x}$ & $0.194 \mathrm{de}$ & $11.1 \mathrm{~b}$ & $5.17 \mathrm{ab}$ & $0.47 \mathrm{a}$ \\
\hline & SD & 0.002 & 1.56 & 0.06 & 0.06 \\
\hline Gallic acid & $\bar{x}$ & $0.091 \mathrm{~b}$ & $17.2 \mathrm{bc}$ & $11.05 \mathrm{c}$ & $0.64 \mathrm{a}$ \\
\hline \multirow[t]{2}{*}{ Quercetin } & $\bar{x}$ & $0.124 \mathrm{c}$ & $25.7 \mathrm{de}$ & $8.07 \mathrm{bc}$ & $0.32 \mathrm{a}$ \\
\hline & SD & 0.001 & 4.46 & 0.09 & 0.05 \\
\hline Trolox & $\bar{x}$ & $0.199 \mathrm{e}$ & $4.1 \mathrm{a}$ & $5.05 \mathrm{ab}$ & $1.24 \mathrm{~b}$ \\
\hline & SD & 0.001 & 0.01 & 0.03 & 0.01 \\
\hline \multirow[t]{2}{*}{$(+)$-Catechin } & $\bar{x}$ & $0.174 \mathrm{~d}$ & $32.4 \mathrm{f}$ & $5.76 \mathrm{ab}$ & $0.18 \mathrm{a}$ \\
\hline & SD & 0.002 & 2.26 & 0.07 & 0.01 \\
\hline \multirow[t]{2}{*}{$F_{\text {olig }}$} & $\bar{x}$ & $0.018 \mathrm{a}$ & $30.9 \mathrm{ef}$ & $55.25 \mathrm{~d}$ & $1.79 \mathrm{~b}$ \\
\hline & SD & 0.001 & 1.27 & 0.43 & 0.06 \\
\hline$F_{\text {poly }}$ & $\bar{x}$ & $0.005 \mathrm{a}$ & $23.5 \mathrm{~cd}$ & $186.93 \mathrm{e}$ & $7.97 \mathrm{~d}$ \\
\hline
\end{tabular}

$\bar{x}=$ mean value, $\mathrm{SD}=$ standard deviation. $F_{\text {olig }}=$ Total oligomeric procyanidin fraction; $F_{\text {poly }}=$ Total polymeric procyanidin fraction. Different letter in the same column means very significant differences, $p<0.001$. 
is much lower than that of ascorbic acid, indicating the latter may have more antiradical efficiency. From this sense, the parameter $\mathrm{AE}$ which considers both antiradical power $\left(1 / \mathrm{EC}_{50}\right)$ and time to reach a steady state of the reaction $\left(T_{\mathrm{EC} 50}\right)$ may be more efficient to discriminate the different tested phenolic compounds than ARP alone.

\subsection{3. $\left(\left\{\mathrm{O}_{2}^{--}\right\}\right)$scavenging capacity}

The $\mathrm{O}_{2}^{--}$scavenging capacity of each tested compound can be expressed by the percentage of inhibition (\% inhibition) of NBT reduction induced by $\mathrm{O}_{2}^{-}$generated by xanthine-xanthine oxidase system and also the initial rate $\left(V_{0}\right)$ of the kinetic reaction. For all tested compounds, the maximum absorbance is reached at $20 \mathrm{~min}$ of reaction. Thus, the $\%$ inhibition and the $V_{0}$ can be determined. These results are presented in Table 7 .

It is worth noting that the $\mathrm{O}_{2}^{--}$scavenging activity of each tested compound increased dose-dependently at a certain molar concentration range. When the concentration of a tested compound was lower than this range, no apparent inhibition reaction could be observed and if its concentration was higher than this range, the percentage of inhibiting NBT reduction reached $100 \%$ immediately (data not shown). Table 7 shows that all tested compounds decreased the reduction of NBT by $\mathrm{O}_{2}^{--}$. The measured rates of reduction were significantly lesser than the control rate for all tested compounds except for trolox. On an equimolar basis and considering both the $\%$ inhibition and the $V_{0}$, catechin appeared higher $\mathrm{O}_{2}^{--}$scavenging activity than gallic acid; ascorbic acid (vitamin C) presents similar capacity of inhibiting NBT reduction but its $V_{0}$ value is significantly higher than that of catechin, indicating the latter is more efficient as $\mathrm{O}_{2}^{-}$scavenger. The $\mathrm{O}_{2}^{--}$scavenging activity of trolox (a water-soluble synthetic analogue of $\alpha$-tocopherol) is arguable. Although trolox presents much higher capacity of inhibiting NBT reduction than simple phenolics catechin and gallic acid and also ascorbic acid, its $V_{0}$ was not significantly different from that of control. In other words, this compound only appears its strong $\mathrm{O}_{2}^{-}$scavenging activity after a prolonged reaction time.

Table 7

Initial rate $\left(V_{0}\right)$ of the kinetic reaction and the percentage of inhibition of NBT reduction (\% inhibition) of the tested antioxidant compounds

\begin{tabular}{llll}
\hline $\begin{array}{l}\text { Antioxidant } \\
\text { compounds }\end{array}$ & Concentration & $V_{0}\left(\Delta A, \mathrm{~s}^{-1}\right)$ & $\%$ Inhibition \\
\hline Control & - & $(1.53 \pm 0.114) \times 10^{-3}$ & 0 \\
SOD & $400 \mu / \mathrm{mL}$ & $(2.95 \pm 0.212) \times 10^{-4 *}$ & $36 \pm 0.85^{\dagger}$ \\
Trolox & $0.20 \mathrm{mM}$ & $(1.03 \pm 0.123) \times 10^{-3}$ & $26 \pm 0.64^{\dagger}$ \\
Gallic acid & $0.20 \mathrm{mM}$ & $(2.07 \pm 0.106) \times 10^{-4 *}$ & $7 \pm 0.42^{\dagger}$ \\
Ascorbic acid & $0.20 \mathrm{mM}$ & $(3.16 \pm 0.229) \times 10^{-4 *}$ & $15 \pm 2.19^{\dagger}$ \\
$(+)$-Catechin & $0.20 \mathrm{mM}$ & $(1.67 \pm 0.120) \times 10^{-4 *}$ & $13 \pm 0.49^{\dagger}$ \\
$F_{\text {olig }}$ & $0.05 \mathrm{mM}$ & $(2.68 \pm 0.120) \times 10^{-4 *}$ & $52 \pm 0.85^{\dagger}$ \\
$F_{\text {poly }}$ & $0.01 \mathrm{mM}$ & $(1.91 \pm 0.311) \times 10^{-4 *}$ & $60 \pm 7.50^{\dagger}$ \\
\hline
\end{tabular}

The symbols ${ }^{*}$ and ${ }^{\dagger}$ indicate very significant difference $p<0.01$ with respect to control. $F_{\text {olig }}=$ Total oligomeric procyanidin fraction; $F_{\text {poly }}=$ Total polymeric procyanidin fraction.
Concerning $F_{\text {olig }}$ and $F_{\text {poly }}$, both of them inhibited $100 \%$ NBT reduction immediately at the same molar concentration as other compounds, so it was impossible to assay the $\mathrm{O}_{2}^{-}$scavenging activity of these procyanidin fractions with other tested compounds in an equal molar concentration. However, even though much lower concentrations of procyanidin fractions were used, much higher values of $\%$ inhibition were obtained, indicating that procyanidins have much higher $\mathrm{O}_{2}^{--}$scavenging activity than other antioxidants. Moreover, $F_{\text {poly }}$ presented higher $\mathrm{O}_{2}^{--}$scavenging activity than $F_{\text {olig, }}$, even though the concentration used for the former was fivefold less than that of the latter. These results show that the grape seed procyanidins may be considered as potent antioxidants and their $\mathrm{O}_{2}^{-}$scavenging capacities are positively related to their degree of polymerization. Similar effect was also observed by Yamaguchi, Yoshimura, Nakazawa, and Ariga (1999), who reported that the higher the polymerization degree of flavanols is, the stronger the superoxide-scavenging activity is.

\subsection{4. $\mathrm{HO}^{*}$ scavenging activity}

Fig. 4 presents plots of $1 / A$ against the concentration $(\mathrm{mM})$ of various tested compounds. It can be seen that the linearity of all plots obtained was good $\left(R^{2}>0.96\right)$. It is evident that for all tested compounds, its scavenging activity on hydroxyl radical increased as its concentration increased in a certain concentration range. According to these results, the rate constant of the reaction (RC) of each tested compound with $\mathrm{HO}^{*}$ can be calculated and given in Fig. 4.

The RC value of each tested compound is directly related with its scavenging activity on $\mathrm{HO}$. Thus, oligomeric and polymeric procyanidins are potent hydroxyl radical scavengers, as compared with some well-known antioxidants - ethanol, mannitol (a selective hydroxy radical scavenger), and acetylsalicylic acid. Furthermore, the $\mathrm{HO}^{*}$ scavenging activity of procyanidins appeared positively related with their degree of polymerization (polymeric procyanidins $>$ oligomeric procyanidins $>$ catechin).

\section{Discussion}

The knowledge of the chemical composition and the purity of procyanidin fractions obtained from grape seed are essential, which provide a base to further study their chemical properties. For this reason, the oligomeric and polymeric procyanidin fractions obtained from grape seed were firstly characterized. Both thioacidolysis-HPLC and ESI-MS analyses appeared very powerful in characterization of these oligomeric and polymeric procyanidin fractions. Combination of these two analytical techniques provided more complete structural information than any of their alone. The mDP of the subfraction $\mathrm{VI}^{\prime}$ of $F_{\text {poly }}$ determined by thioacidolysis-HPLC $(34.5 \pm 2.89)$, is the highest value in grape seeds reported until now. The results of ESI-MS analysis of the subfractions from $F_{\text {olig }}$ and $F_{\text {poly }}$ were in agreement with those from thioacidolysis-HPLC. 

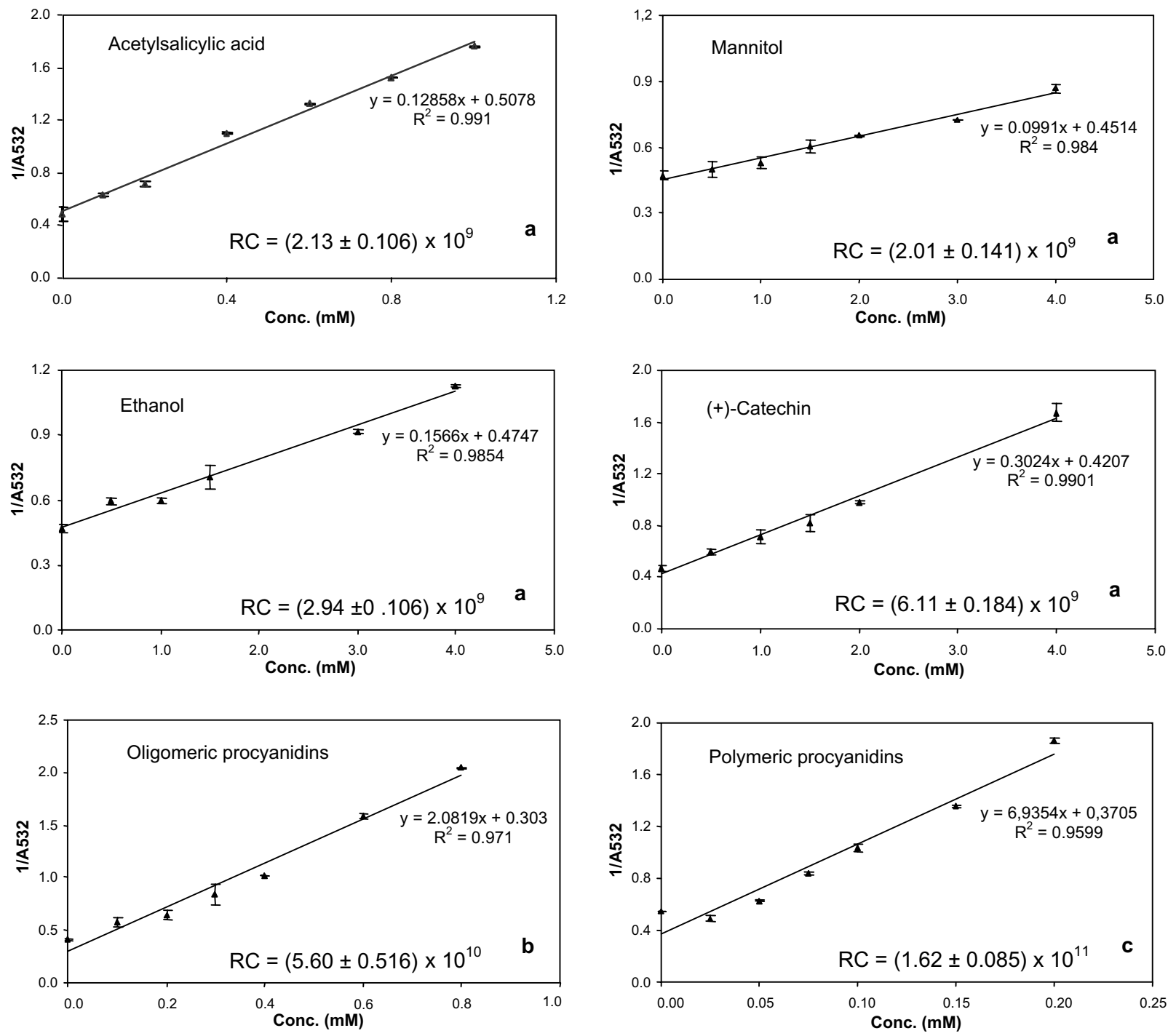

Fig. 4. Hydroxyl radical (HO') scavenging capacity of various antioxidant compounds. RC - rate constant $\left(\mathrm{M}^{-1} \mathrm{~s}^{-1}\right)$. Different superscript letter after the $\mathrm{RC}$ values are significantly different $(p<0.001)$.

Due to the fact that there were no established or routine methods of determining the purity of procyanidin mixture samples, we combined various methods to verify the purity of our oligomeric and polymeric procyanidin fractions. From these results, we may conclude that both oligomeric and polymeric procyanidin fractions have high purity (over 92\%) and lack of sugars, nitrogenous compounds and several metals. The high purity of the oligomeric and polymeric procyanidin fractions is important to ensure the validation of further study on their chemical properties.

Since the methods for assessing antioxidant activity vary considerably, depending on the type of radicals that is generated, and that for a given compound, the results obtained by different methods are not always comparable, the present work evaluated the antioxidant activities of the tested compounds by determining their scavenger capacity on different type of radicals. Interestingly, all these tested methods have shown that, on an equimolar basis, polymeric procyanidins appeared the highest antioxidant activities, followed oligomeric procyanidins, whereas catechins presented lower antioxidant activities than its oligomers and polymers. In other words, the antioxidant activities of grape seed procyanidins are positively related to their degree of polymerization. Moreover, procyanidins presented higher antioxidant activities than other antioxidants such as vitamin C. This would indicate that grape seed procyanidins might be of interest to be used as substituted or alternative antioxidants.

\section{Acknowledgments}

We are particularly grateful to the Instituto Nacional de Recursos Biológicos (ex-INIAP) and the Fundação para a Ciência e a Technologia for financial support (PIDDAC- 
INIA and PARLE-FCT). We also gratefully acknowledge Engineer Conçeicão Leandro for technical assistance, Prof. Maria Candida Vaz for help in some elemental analysis, Master Sofia Catarino for help in heavy metal analysis, Engineer Pedro Barros for help in some metal analysis and Mrs. Graziela Rodrigues for help in analysis of total nitrogen and total sugar.

\section{References}

Aruoma, O. I., Murcia, A., Butler, J., \& Halliwell, B. (1993). Evaluation of the antioxidant and prooxidant actions of gallic acid and its derivatives. Journal of Agricultural and Food Chemistry, 41(11), 1880-1885.

Aviram, M., \& Fuhrman, B. (1998). Polyphenolic flavonoids inhibit macrophage-mediated oxidation of LDL and attenuate atherogenesis. Atherosclerosis, 137 Suppl. S1, S45-S50.

Barato, M. C., Tattini, M., Galardi, C., Pinelli, P., Romani, A., Visioli, F., et al. (2003). Antioxidant activity of galloyl quinic derivatives isolated from P. Lentiscus leaves. Free Radical Research, 37(4), 405-412.

Brand-Williams, W., Cuvelier, M. E., \& Berset, C. (1995). Use of a free radical method to evaluate antioxidant activity. Lebensmittel-Wissenschaft Und-Technologie, 28(1), 25-30.

Brun, S. (1979). Determination des composés phénoliques totaux par le reactif de Folin-Ciocalteu. Feuillet Vert O.I.V., 681.

Carando, S., Teissedre, P. L., \& Cabanis, J. C. (1999). Estimation of catechins and procyanidins intake relative to a moderate and regularly consumption of wine in France. Bulletin de l'OIV, 815-816, 73-86.

Catarino, S., \& Curvelo-Garcia, A. S. (1999). Les teneurs en plomb et en cadmium de quelques vins portugais. Feuillet Vert O.I.V., 1081.

Cheynier, V. (2000). Grape polyphenols and their reactions in wine. In S. Martens, D. Treutter, \& G. Forkmann (Eds.), Polyphenols (pp. 1-14). Freising-Weihenstephan: TUM.

CT83 (1988). Determinação do teor de açúcares totais. In IPQ, Bebidas alcoólicas e espirituosas, Norma Portuguesa NP - 2224, Lisboa.

Halliwell, B., Gutteridge, J. M., \& Aruoma, O. (1987). The deoxyribose method: A simple "Test-Tube" assay for determination of rate constants for reactions of hydroxyl radicals. Analytical Biochemistry, 165(1), 215-219.

Hayasaka, Y., Waters, E. J., Cheynier, V., Herderich, M. J., \& Vidal, S. (2003). Characterization of proanthocyanidins in grape seeds using electrospray mass spectrometry. Rapid Communications in Mass Spectrometry, 17(1), 9-16.

Huang, D., Ou, B., \& Prior, R. (2005). The chemistry behind antioxidant capacity assays. Journal of Agricultural and Food Chemistry, 53(6), 1841-1856.

Kramling, T. E., \& Singleton, V. L. (1969). An estimate of the nonflavanoid phenols in wines. American Journal of Enology and Viticulture, 20(2), 86-92.

Labarbe, B., Cheynier, V., Brossaud, F., Souquet, J.-M., \& Moutounet, M. (1999). Quantitative fractionation of grape proanthocyanidins according to their degree of polymerization. Journal of Agricultural and Food Chemistry, 47(7), 2719-2723.

Laughton, M. J., Halliwell, B., Evans, P. J., \& Hoult, J. R. (1989). Antioxidant and pro-oxidant actions of the plant phenolics quercetin, gossypol and myricetin. Biochemical Pharmacology, 38(17), 2859-2865.

Maffei Facino, R., Carini, M., Aldini, G., Bombardelli, E., Morazzoni, P., \& Morelli, R. (1994). Free radicals scavenging action and anti-enzyme activities of procyanidines from Vitis vinifera A mechanism for their capillary protective action. Arzneimittelforschung, 44(5), 592-601.

McCord, J. M., \& Fridovich, I. (1969). Superoxide dismutase. An enzymic function for erythrocuprein (hemocuprein). Journal of Biological Chemistry, 244(22), 6049-6055.

O.I.V. (1990). In OIV, Recueil des méthodes internationales d'analyse des vins (pp. 368). Paris.
Ohinishi, M., Morishita, H., Iwahashi, H., Toda, S., Shirataki, Y., Kimura, M., et al. (1994). Inhibitory effects of chlorogenic acids on linoleic acid peroxidation and haemolysis. Phytochemistry, 36(3), 579-583.

Porter, L. J. (1988). Flavans and proanthocyanidins. In J. B. Harborne (Ed.), The flavonoids advances in research since 1980 (pp. 21-62). London and New York: Chapman and Hall.

Prieur, C., Rigaud, J., Cheynier, V., \& Moutounet, M. (1994). Oligomeric and polymeric procyanidins from grape seeds. Phytochemistry, 36(3), 781-784.

Renauld, S., \& De Lorgeril, M. (1992). Wine, alcohol, platelets, and the French paradox for coronary heart disease. Lancet, 339(8808), 1523-1526.

Ricardo-da-Silva, J. M. (1992). Procyanidines du raisin et du vin. Structure et proprietés chimiques, (pp. 257). PhD thesis, ENSAM, France.

Ricardo-da-Silva, J. M., Darmon, N., Fernández, Y., \& Mitjavila, S. (1991). Oxygen free radical scavenger capacity in aqueous models of different procyanidins from grape seeds. Journal of Agricultural and Food Chemistry, 39(9), 1549-1552.

Ricardo-da-Silva, J. M., Rigaud, J., Cheynier, V., Cheminat, A., \& Moutounet, M. (1991). Procyanidin dimers and trimers from grape seeds. Phytochemistry, 30(4), 1259-1264.

Rigaud, J., Escribano-Bailon, M. T., Prieur, C., Souquet, J.-M., \& Cheynier, V. (1993). Normal-phase high-performance liquid chromatographic separation of procyanidins from cacao beans and grape seeds. Journal of Chromatography A, 654(2), 255-260.

Sánchez-Moreno, C., Larrauri, J. A., \& Saura-Calixto, F. (1998). A procedure to measure the antiradical efficiency of polyphenols. Journal of the Science of Food and Agricultural, 76(2), 270-276.

Souquet, J.-M., Labarbe, B., Le Guernevé, C., Cheynier, V., \& Moutounet, M. (2000). Phenolic composition of grape stems. Journal of Agricultural and Food Chemistry, 48(4), 1076-1080.

Spranger, M. I., Sun, B. S., Leandro, M. C., Carvalho, E. C., \& Belchior, A. P. (1998). Changes in anthocyanins, catechins and proanthocyanidins during fermentation and early post-fermentation of red grapes. In Proceeding of XXIII word congress on vine and wine (pp. II-183-II-189). Lisbon: Portugal.

Sun, B. S., Belchior, G. P., Ricardo-da-Silva, J. M., \& Spranger, M. I. (1999b). Isolation and purification of dimeric and trimeric procyanidins from grape seeds. Journal of Chromatography A, 841(1), 115-121.

Sun, B. S., Leandro, M. C., Ricardo-da-Silva, J. M., \& Spranger, M. I. (1998). Separation of grape and wine proanthocyanidins according to their degree of polymerisation. Journal of Agricultural and Food Chemistry, 46(4), 1390-1396.

Sun, B. S., Pinto, T., Leandro, M. C., Ricardo-da-Silva, J. M., \& Spranger, M. I. (1999a). Transfer of catechins and proanthocyanidins from solid parts of the grape cluster into wine. American Journal of Enology and Viticulture, 50(2), 179-184.

Takechi, M., Tanaka, Y., Takehara, M., Nonaka, G. I., \& Nishioka, I. (1985). Structure and antiherpetic activity among the tannins. Phytochemistry, 24(10), 2245-2250.

Vinson, J. A., Dabbagh, Y. A., Sherry, M. M., \& Jang, J. (1995). Plant flavonoids, especially tea flavonols, are powerful antioxidants using an in vitro oxidation model for heart disease. Journal of Agricultural and Food Chemistry, 43(11), 2800-2802.

Yamaguchi, F., Yoshimura, Y., Nakazawa, H., \& Ariga, T. (1999). Free radical scavenging activity of grape seed extract and antioxidants by electron spin resonance spectrometry in an $\mathrm{H}_{2} \mathrm{O}_{2} / \mathrm{NaOH} / \mathrm{DMSO}$ system. Journal of Agricultural and Food Chemistry, 47(7), 2544-2548.

Yamakoshi, J., Kataoka, S., Koga, T., \& Ariga, T. (1999). Proanthocyanidin-rich extract from grape seeds attenuates the development of aortic atherosclerosis in cholesterol-fed rabbits. Atherosclerosis, 142(1), 139-149.

Yamakoshi, J., Saito, M., Kataoka, S., \& Tokutake, S. (2002). Procyanidin-rich extract from grape seeds prevents cataract formation in 
hereditary cataractous rats. Journal of Agricultural and Food Chemistry, 50(17), 4983-4988.

Yoshida, T., Mori, K., Hatano, T., Okumura, T., Uehara, I., Komagoe, K., et al. (1989). Studies on inhibition mechanism of autoxidation by tannins and flavonoids. V. Radical-scavenging effects of tannins and related polyphenols on 1,1-diphenyl-2-picrylhydrazyl radical. Chemical \& Pharmaceutical Bulletin, 37(7), 1919-1921. 